\title{
Contactless graphene conductance measurements: the effect of device fabrication on terahertz time-domain spectroscopy
}

Mackenzie, David; Buron, Jonas Christian Due; Bøggild, Peter; Jepsen, Peter Uhd; Petersen, Dirch Hjorth

Published in:

International Journal of Nanotechnology

Link to article, DOI:

10.1504/IJNT.2016.079660

Publication date:

2016

Document Version

Peer reviewed version

Link back to DTU Orbit

Citation (APA):

Mackenzie, D., Buron, J. C. D., Bøggild, P., Jepsen, P. U., \& Petersen, D. H. (2016). Contactless graphene conductance measurements: the effect of device fabrication on terahertz time-domain spectroscopy.

International Journal of Nanotechnology, 13(8-9), 591-596. https://doi.org/10.1504/IJNT.2016.079660

\section{General rights}

Copyright and moral rights for the publications made accessible in the public portal are retained by the authors and/or other copyright owners and it is a condition of accessing publications that users recognise and abide by the legal requirements associated with these rights.

- Users may download and print one copy of any publication from the public portal for the purpose of private study or research.

- You may not further distribute the material or use it for any profit-making activity or commercial gain

- You may freely distribute the URL identifying the publication in the public portal 


\title{
Contactless graphene conductance measurements: the effect of device fabrication on terahertz time-domain spectroscopy
}

\section{David M.A. Mackenzie*, Jonas D. Buron and Peter Bøggild}

Department of Micro and Nanotechnology,

Technical University of Denmark,

Building 345B, 2800 Kgs., Denmark

and

Center for Nanostructured Graphene (CNG),

Technical University of Denmark,

2800 Kgs., Denmark

Email: dmac@nanotech.dtu.dk

Email: jcdb@nanotech.dtu.dk

Email: peter.boggild@nanotech.dtu.dk

${ }^{*}$ Corresponding author

\section{Peter U. Jepsen}

Department of Photonics, Technical University of Denmark, Building 345A, 2800 Kgs., Denmark

Email: puje@fotonik.dtu.dk

\section{Dirch H. Petersen}

Department of Micro and Nanotechnology, Technical University of Denmark, Building 345B, 2800 Kgs., Denmark and

Center for Nanostructured Graphene (CNG), Technical University of Denmark, 2800 Kgs., Denmark

Email: dhpe@nanotech.dtu.dk

\begin{abstract}
We perform contactless full-wafer maps of the electrical conductance of a 4-inch wafer of single-layer CVD graphene using terahertz time-domain spectroscopy both before and after deposition of metal contacts and fabrication of devices via laser ablation. We find that there is no significant change in the measured conductance of graphene before and
\end{abstract}


after device fabrication. We also show that precise terahertz time-domain spectroscopy can be performed when the beam spot is at sufficient distance $(>1.2 \mathrm{~mm})$ from metal contacts.

Keywords: CVD graphene; terahertz time-domain spectroscopy; laser ablation; T-ray.

Reference to this paper should be made as follows: Mackenzie, D.M.A., Buron, J.D., Bøggild, P., Jepsen, P.U. and Petersen, D.H. (2016) 'Contactless graphene conductance measurements: the effect of device fabrication on terahertz time-domain spectroscopy', Int. J. Nanotechnol., Vol. 13, Nos. 8/9, pp.591-596.

Biographical notes: David Michael Angus Mackenzie graduated from the University of Canterbury in 2010 with a PhD in Physics based on nanoscale cluster devices. He joined the Micro and Nanotechnology Department at the Technical University of Denmark in 2012 as a Postdoctoral Researcher where he now works with graphene devices including nanopatterned transistors, nanopatterned gas sensors and large-area 2D-material devices.

Jonas Due Buron graduated from the Technical University of Denmark in 2013 with a $\mathrm{PhD}$ in Applied Physics focusing on terahertz spectroscopy of nanomaterials. He is currently a Postdoctoral Researcher at the Department of Micro and Nanotechnology at the Technical University of Denmark, where he works on development of methods for electrical characterisation of ultrathin materials.

Peter Bøggild graduated from Copenhagen University in 1998 with a $\mathrm{PhD}$ in Physics based on low-temperature ballistic transport in 2D electron gases and is leading a research group at the Technical University of Denmark, which explores graphene and other 2D-materials, devices and applications.

Peter Uhd Jepsen obtained the $\mathrm{PhD}$ degree from Aarhus University in 1996 with a thesis on ultrafast terahertz science and technology. He was Postdoc and Assistant Professor at Freiburg University from 1996 to 2004, and has been at DTU Fotonik at the Technical University of Denmark since 2005, where he is now Professor, leading a research group exploring linear and nonlinear low-energy phenomena in solid-state physics and chemistry using ultrafast terahertz spectroscopy.

Dirch Hjorth Petersen obtained a $\mathrm{PhD}$ in Applied Physics from the Technical University of Denmark in 2010. He is currently a Senior Researcher focused on development of methods for electrical characterisation of ultrathin materials.

\section{Introduction}

As commercial graphene applications are developing there is an increasing demand for high-quality large-area graphene. Many lithography-based methods for determining the electrical properties of graphene necessarily require metals, solvents and resists, which are known to adversely affect electrical properties [1-3]. Therefore, methods for determining electrical properties that require no physical contact with the graphene are 
preferred, and one such method is terahertz time-domain spectroscopy (THz-TDS). THz-TDS has shown to be a viable method for obtaining electrical parameters from graphene, such as conductance [4,5], carrier mobility [6] and field-effect properties [7]. It is and will continue to be important to benchmark THz-TDS against standard electrical measurements. Here we show that the conductance of graphene measured (as by THz-TDS) is not significantly affected by fabrication of graphene devices by shadow-mask metal deposition and subsequent laser ablation graphene patterning.

\section{Methods}

All measurements took place on a THz-transparent double-sided-polished high resistivity $(>10 \mathrm{k} \Omega \mathrm{cm})$ silicon wafer, as shown in Figure 1(a), with a highly p-doped $\left(n=2.6 \times 10^{19} \mathrm{~cm}^{-3}\right)$ polysilicon layer, and an insulating layer of $165 \mathrm{~nm} \mathrm{a} \mathrm{Si}_{3} \mathrm{~N}_{4}$. Single layer graphene was then transferred on top of the $\mathrm{Si}_{3} \mathrm{~N}_{4}$. The frequency dependent graphene sheet conductance was mapped by raster-scanned non-contact transmission THz-TDS at normal incidence, using a Picometrix T-ray 4000 fibre-coupled spectrometer in the range of $0.25-1.2 \mathrm{THz}$ [7]. The frequency range corresponds to wavelengths of $1.2-0.25 \mathrm{~mm}$, which then represents the maximal spatial resolution. $\sigma_{D C}$ was determined in each pixel of the scan by fitting the Drude model,

$$
\sigma_{\text {real }}(\omega)=\frac{\sigma_{\mathrm{DC}}}{1+(\omega \tau)^{2}}
$$

to the real part of the measured sheet conductance spectra.

Devices were fabricated using a laser ablation method shown in Figure 1 and outlined in Mackenzie et al. [8]. Initially, metal contacts ( $5 \mathrm{~nm} \mathrm{Cr}, 45 \mathrm{~nm} \mathrm{Au}$ ) were deposited via electron-beam evaporation through a shadow mask using a Wordentec QCL 800, as shown in Figure 1(b). Selective laser ablation of the graphene was performed using a 3D-Micromac AG microSTRUCT vario with a 10 ps $1064 \mathrm{~nm}$ pulsed laser, without damaging the underlying substrate, as shown in Figure 1(c). The resulting square device with centre area of $5 \times 5 \mathrm{~mm}^{2}$ is illustrated in Figure 1(d). An advantage of this fabrication method is that the device area does not require contact with solvents or resists, which are known to affect the electrical properties of graphene [1-3].

Figure 1 Schematic showing fabrication of graphene devices using laser ablation. (a) Initially graphene is transferred to a silicon four-inch wafer with silicon nitride layer. (b) $5 \mathrm{~nm} \mathrm{Cr}, 45 \mathrm{~nm} \mathrm{Au}$ is deposited using electron beam evaporation and a shadow mask. (c) Definition of devices via selective ablation of graphene using a $10 \mathrm{ps} 1064 \mathrm{~nm}$ pulsed laser. (d) Final device, square of $5 \times 5 \mathrm{~mm}^{2}$ (see online version for colours)

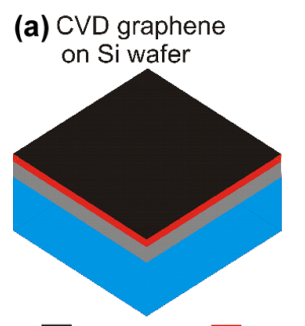

(b) Metal evaporation with shadow mask

Graphene

$\mathrm{Si}_{3} \mathrm{~N}_{4}$
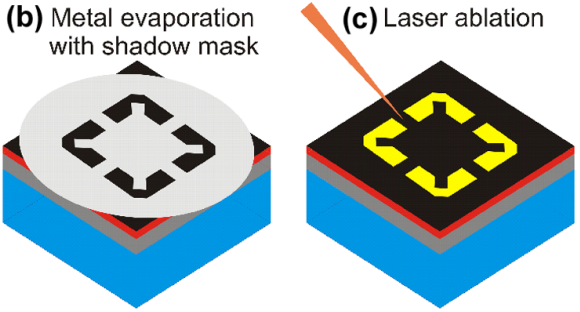

(d) Device defined

Polysilicon Silicon

Shadow Mask Chrome/Gold ps laser 


\section{Results and discussion}

Our results are summarised in Figure 2. Figure 2(a) and (b) show the full wafer THz-TDS $\sigma_{D C}$ maps before and after device fabrication, respectively. Maps were performed with a step size (and corresponding pixel size) of $400 \mu \mathrm{m}$. Because the THz-TDS signal at the contacts is dominated by the high conductance of the metal relative to the graphene, large values of conductance, which cannot be attributed to graphene $(\sigma>10 \mathrm{mS})$ are set to zero in the dataset, and correspond to white on Figure 2(a) and (b). The THz spot profile is approximately Gaussian with a frequency dependent FWHM, which is comparable to the wavelength. Figure 2(c) shows how the mean conductance value changes when areas of different proximity to the contacts are included. Figure 2(c) inset shows a device with coloured squares corresponding to the areas where the mean is calculated. When pixels closer than $1 \mathrm{~mm}$ to metal (device area greater than $3 \times 3 \mathrm{~mm}^{2}$ ) are included in the analysis, the mean conductance is significantly higher for the post-device measurements. However, the values converge when pixels that are $1.2 \mathrm{~mm}$ or closer to metal are excluded (device areas of maximum size $2.4 \times 2.4 \mathrm{~mm}^{2}$ ). As expected, the device area sampling-size has no effect for the pre-device measurement analysis. Therefore, in the analysis of both pre-device and post-device measurements, only the pixels in centre area of each device $\left(2.4 \times 2.4 \mathrm{~mm}^{2}\right)$ were considered for the remaining analysis.

Figure 2 Full wafer THz spectroscopy maps of a 4-inch graphene-coated wafer (a) before device fabrication and (b) after device fabrication. (c) Average THz conductance as a function of proximity of the THz spot to the metal contacts. Inset: Photograph of fabricated device, with laser-ablated cuts coloured in black for clarity. Each coloured box represents a different $\mathrm{THz}$ averaging area with varying distance to the metal contacts. From black $=0 \mathrm{~mm}$ to light blue $=2 \mathrm{~mm}$. (d) Histograms, showing the distribution of conductances before (blue) and after (red) device fabrication. (e) Pixel-to-pixel correlation of the conductances before and post device fabrication. Each colour represents one device area within which several $\mathrm{THz}$ measurements were performed (see online version for colours)
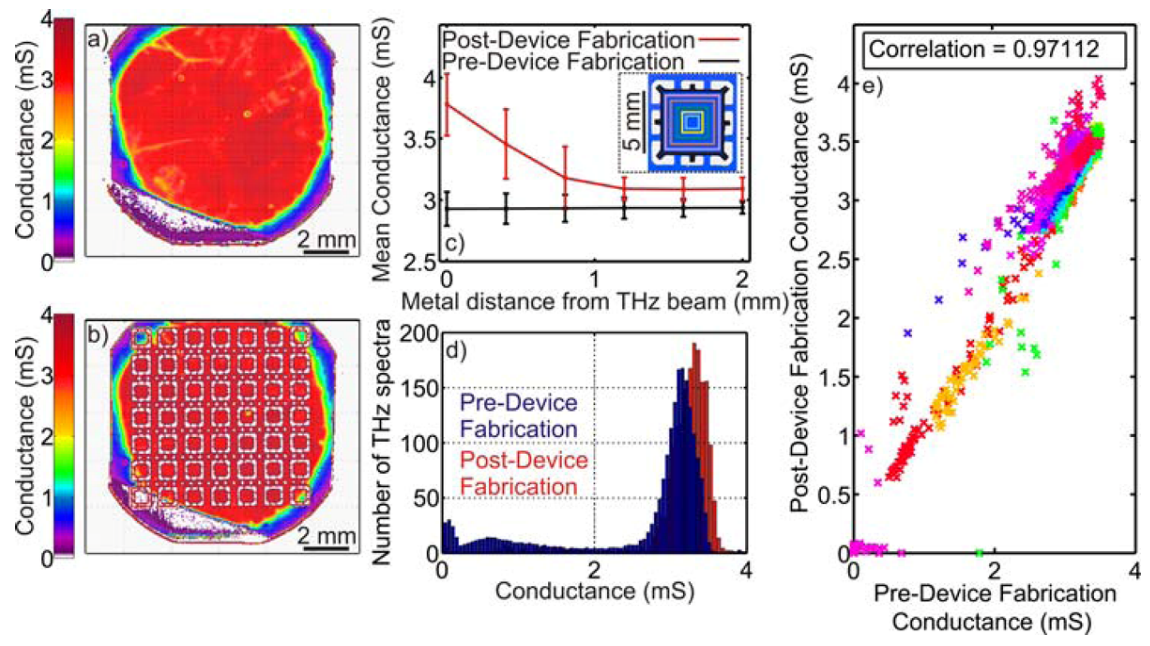

Histograms of the mean conductance inside device areas are shown via histograms in Figure 2(d). The mean of the pre-device fabrication was $2.94 \pm 0.09 \mathrm{mS}$ and the post fabrication mean was $3.09 \pm 0.07 \mathrm{mS}$, with the uncertainty calculated as the standard 
deviation of the device areas. Each individual device area is then compared in a correlation plot in Figure 2(e) with each colour corresponding to one device area. A linear fit produces a slope of 1.009 and a correlation of $R^{2}>0.97$ between each pixel of the THz-TDS maps before and after device definition, which supports the claim of consistency between pre- and post-device fabrication measurements.

Overall, there is a slight increase in measured conductance after fabrication of devices, however the difference is within measurement uncertainties and smaller than pixel-to-pixel variations, especially considering that no effort was made to control the environmental conditions, so any small conductance changes observed are well within differences expected from random variations in humidity and other absorbents on the graphene surface [3].

The two datasets are consistent within measurement uncertainties provided that the $\mathrm{THz}$ measurements are performed at a distance greater than $1.2 \mathrm{~mm}$ away from any metal structures. Overall, the study suggests that graphene properties are not significantly affected by the deposition of contacts and subsequent laser ablation as outlined in Mackenzie et al. [8].

\section{Conclusions}

Wafer maps of electrical conductance were performed before and after device fabrication on a 4-inch graphene-coated wafer. Although a slight increase in conductance was observed over the entire wafer after devices were fabricated, any difference was insignificant compared to measurement uncertainties, device-to-device variations and variations in environmental conditions.

Therefore we conclude that the laser ablation method outlined in Mackenzie et al. [8] does not significantly affect THz-TDS conductance measurements and can serve as a protocol for fast benchmarking in large-scale CVD graphene electrical characterisation.

\section{Acknowledgements}

For funding we would like to acknowledge H.C. Ørsteds foundation, and Villum Fonden project No. VKR023117, and EC Graphene FET Flagship contract number 604391. For help with the project we should like to acknowledge laser process specialists Chantal Silvestre and Peter Jesper Hanberg.

\section{References}

1 Schedin, F., Geim, A.K., Morozov, S.V., Hill, E.W., Blake, P., Katsnelson, M.I. and Novoselov, K.S. (2007) 'Detection of individual gas molecules adsorbed on graphene', Nat. Mater., Vol. 6, pp.652-655.

2 Goossens, A.M., Calado, V.E., Barreiro, A., Watanabe, K., Taniguchi, T. and Vandersypen, L.M.K. (2012) 'Mechanical cleaning of graphene', Appl. Phys. Lett., Vol. 100, p.073110.

3 Gammelgaard, L., Caridad, J.M., Cagliani, A., Mackenzie, D.M.A., Booth, T.J. and Bøggild, P. (2014) 'Graphene transport properties upon exposure to PMMA processing and heat treatments', 2D Mater., Vol. 1, p.035005. 
4 Buron, J.D., Petersen, D.H., Bøggild, P., Cooke, D.G., Hilke, M., Sun, J., Whiteway, E., Nielsen, P.F., Hansen, O., Yurgens, A. and Jepsen, P.U. (2012) 'Graphene conductance uniformity mapping', Nano Lett., Vol. 12, pp.5074-5081.

5 Tomaino, J.L., Jameson, A.D., Kevek, J.W., Paul, M.J., van der Zande, A.M., Barton, R.A., McEuen, P.L., Minot, E.D. and Lee, Y.S. (2011) 'Terahertz imaging and spectroscopy of large-area single-layer graphene', Opt. Express, Vol. 19, pp141-146.

6 Buron, J.D., Pizzocchero, F., Jessen, B.S., Booth, T.J., Nielsen, P.F., Hansen, O., Hilke, M., Whiteway, E., Jepsen, P.U., Bøggild, P. and Petersen, D.H. (2014) 'Electrically continuous graphene from single crystal copper verified by terahertz conductance spectroscopy and micro four-point probe', Nano Lett., Vol. 5, pp.6348-6355.

7 Buron, J.D., Pizzocchero, F., Jepsen, P.U., Petersen, D.H., Caridad, J.M., Jessen, B.S., Booth, T.J. and Bøggild, P. (2015) 'Graphene mobility mapping', Sci. Rep., Vol. 5, p.12305.

8 Mackenzie, D.M.A., Buron, J.D., Whelan, P.R., Jessen, B.S., Silajdźić, A., Pesquera, A., Centeno, A., Zurutuza, A., Bøggild, P. and Petersen, D.H. (2015) 'Fabrication of CVD graphene-based devices via laser ablation for wafer-scale characterization', 2D Mater., Vol. 2, p.045003. 